University of Nebraska - Lincoln

DigitalCommons@University of Nebraska - Lincoln

May 1998

\title{
THE GROWTH OF STRAINED THIN FILMS OF GADOLINIUM
}

C. Waldfried

University of Nebraska-Lincoln

O. Zeybek

University of Liverpool, Liverpool L69-3BX, UK

T. Bertrams

University of Liverpool, Liverpool L69-3BX, UK

S.C. Barrett

University of Liverpool

Peter A. Dowben

University of Nebraska-Lincoln, pdowben@unl.edu

Follow this and additional works at: https://digitalcommons.unl.edu/physicsdowben

Part of the Physics Commons

Waldfried, C.; Zeybek, O.; Bertrams, T.; Barrett, S.C.; and Dowben, Peter A., "THE GROWTH OF STRAINED THIN FILMS OF GADOLINIUM" (1998). Peter Dowben Publications. 162.

https://digitalcommons.unl.edu/physicsdowben/162

This Article is brought to you for free and open access by the Research Papers in Physics and Astronomy at DigitalCommons@University of Nebraska - Lincoln. It has been accepted for inclusion in Peter Dowben Publications by an authorized administrator of DigitalCommons@University of Nebraska - Lincoln. 


\title{
THE GROWTH OF STRAINED THIN FILMS OF GADOLINIUM
}

\author{
C. WALDFRIED*, O. ZEYBEK**, T. BERTRAMS**, S. D. BARRETT***, P.A. \\ DOWBEN*
}

*Department of Physics and Astronomy and the Center for Materials Research and Analysis University of Nebraska, Lincoln, Nebraska 68588-0111, USA

${ }^{* *}$ Surface Science Research Center,University of Liverpool, Liverpool L69-3BX, UK

***Surface Science Research Center and Department of Physics, University of Liverpool, Liverpool L69-3BX, UK

\section{ABSTRACT}

The growth of strained thin films of gadolinium has been investigated with low-energy electron diffraction (LEED) and scanning tunneling microscopy (STM) and compared to the film growth of unstrained gadolinium. Strained thin films of gadolinium are distinct from the unstrained films by a substrate induced preferential domain growth direction, which is also reflected in the electronic structure.

\section{INTRODUCTION}

The substrate can have significant influence on the crystalline structure and domain growth mode of thin metal films. We were successful in obtaining strained thin films of gadolinium by growing Gd on a corrugated $M o(112)$ substrate [1-6], as opposed to W(110) [7], which supports relatively "unstrained" Gd(0001) films. This paper describes the altered film growth of strained thin films of Gd, generated by the different substrate. The thickness dependent crystalline structure and domain growth mode of thin films of Gd grown on Mo(112) has been determined by low energy electron diffraction (LEED) and scanning tunneling microscopy (STM).

\section{EXPERIMENT}

The LEED studies were performed with an Omicron 4 grid LEED system in a UHV chamber with a base pressure of $7 \times 10^{-11}$ Torr. Submonolayer ( $<<1 \mathrm{ML}$ ), ultra-thin ( $3 \mathrm{ML}<\mathrm{d}$ $<10 \mathrm{ML}$ ) and thin films (d >10 ML) of strained Gd were grown on the Mo(112) crystal by slow physical evaporation and deposition ( $1-2 \AA / \mathrm{min})$. The chamber pressures during deposition were less than $1.5 \times 10^{-10}$ Torr. The Gd film thickness was monitored with a quartz- 
crystal oscillator that was calibrated by means of the Mo $4 \mathrm{p}$ and $\mathrm{Gd} 4 \mathrm{f}$ core level intensities in conjunction with the well defined Gd interface structure that is formed at a coverage of $2 / 3$ monolayer [6]. The films were consequently annealed at approximately $650 \mathrm{~K}$ (submonolayer films), $500 \mathrm{~K}$ (ultra-thin films), and up to $800 \mathrm{~K}$ (thin films) for 5 minutes to obtain maximum structural order.

The STM experiments were carried out with an Omicron room temperature UHV STM in a different UHV system at the Surface Science Research Center in Liverpool, UK. All measurements were performed in the constant current mode at a base pressure of $1.0 \times 10^{-10}$ Torr or better. Thin films of strained and unstrained gadolinium, approximately 15 to 50 monolayers thick, were grown at room temperature on a $\mathrm{Mo}(112)$ and $\mathrm{W}(110)$ crystal, respectively and annealed to advance the crystalline order. The growth and ordering of the Gd films was monitored by LEED and the cleanliness determined with Auger electron spectroscopy.

\section{RESULTS}

Strained thin films of gadolinium are grown on the corrugated surface of $\mathrm{Mo}(112)$ and characterized by an initial layer-by-layer (van der Merwe) or possibly Stranski-Krastanov growth mode. This growth mode characterization is based on the intensity changes of the $\mathrm{Gd} \mathbf{4 f}$ and substrate Mo 4p core level intensities [6] and is similar to the growth mode of unstrained Gd films, grown on W(110) [8-10].

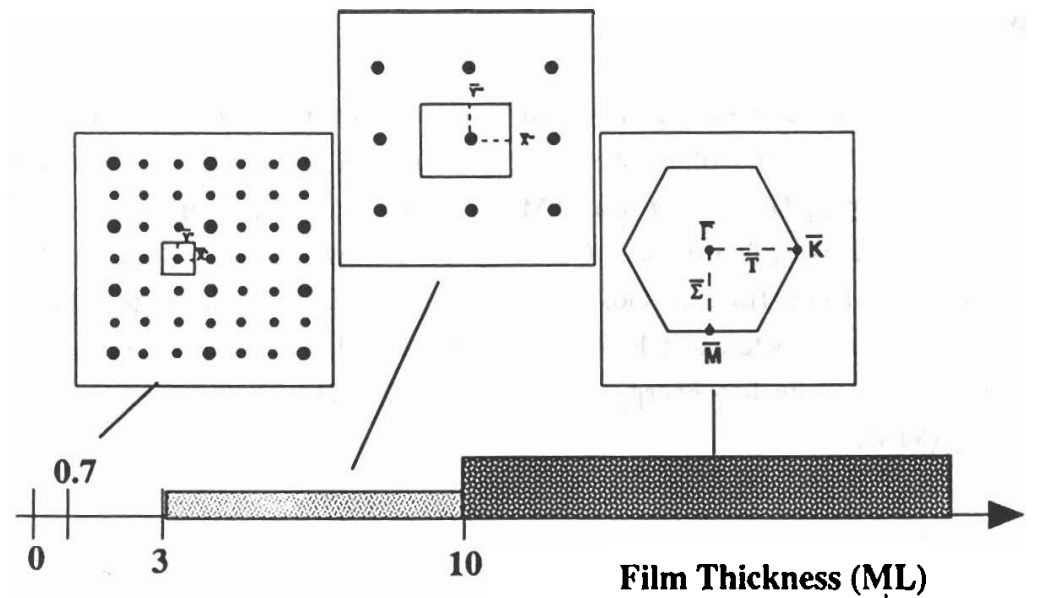

Fig. 1.: The thickness dependent film growth mode of gadolinium grown on Mo(112). At a coverage of $0.7 \mathrm{ML}$ an ordered submonolayer structure is formed with a (3×2) LEED pattern. Ultra-thin films $(3<\mathrm{d}<10 \mathrm{ML})$ order in a rectangular surface Brillouin zone that resembles strained $\mathrm{Gd}(1012)$. Gd films thicker than approximately $10 \mathrm{ML}$ order as strained $\mathrm{Gd}(0001)$ characterized by a hexagonal surface Brillouin zone. 

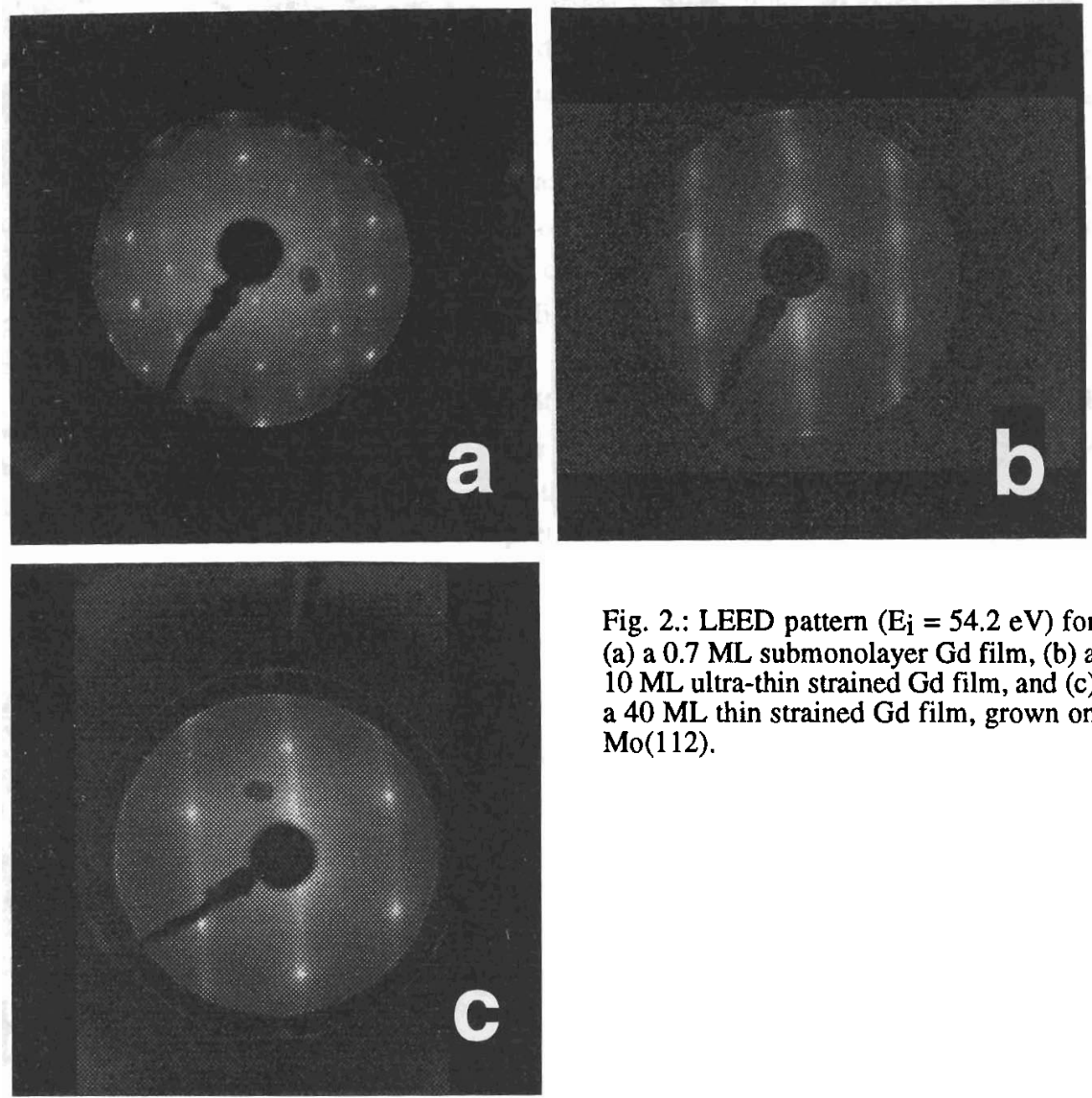

Fig. 2.: LEED pattern $\left(\mathrm{E}_{i}=54.2 \mathrm{eV}\right)$ for (a) a 0.7 ML submonolayer Gd film, (b) a $10 \mathrm{ML}$ ultra-thin strained Gd film, and (c) a $40 \mathrm{ML}$ thin strained Gd film, grown on $\operatorname{Mo}(112)$.

The growth of strained gadolinium films on $\mathrm{Mo}(112)$ adopts at least three different thickness dependent forms (Fig. 1) which has been categorized in (i) the submonolayer regime ( $d \approx 0.7 \mathrm{ML}$ ), (ii) the ultra-thin films ( $3 \mathrm{ML}<\mathrm{d}<10 \mathrm{ML}$ ) and (iii) the thin films ( $>10 \mathrm{ML}$ ). The clean $\mathrm{Mo}(112)$ surface is characterized by a (1x1) LEED pattern $[6,11,12]$ with rectangular surface Brillouin zone (SBZ) and zone dimensions of $1.15 \AA^{-1}$ along the $\overline{\Gamma X}$-direction and $0.706 \AA^{-1}$ along the $\overline{\Gamma Y}$-direction. Deposition of gadolinium, which naturally orders in a hexagonal closed packed (hcp) structure, results in a p(3×2) LEED pattern for the submonolayer regime (Fig. 2a), a rectangular $p(1 \times 1)$ LEED pattern, that resembles strained $G d(1012)$ for the ultra-thin films (Fig. 2b) and a streaked hexagonal LEED pattern, that resembles strained $\mathrm{Gd}(0001)$ for the thin films (Fig. 2c). The strain of the latter two structures is such that the lattice 

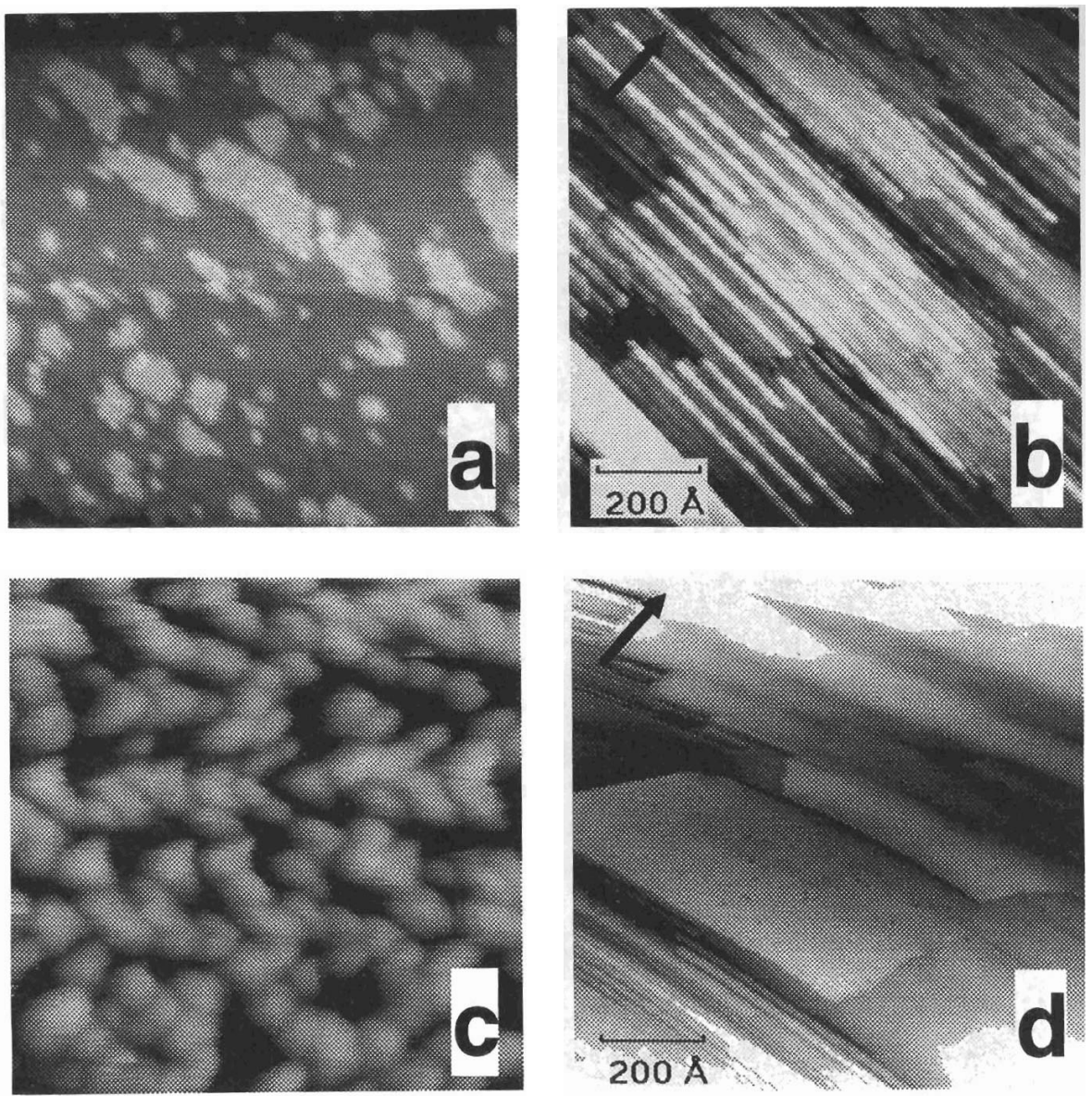

Fig. 3. STM images ( $1000 \times 1000 \AA$ ) for unstrained thin films of Gd (a and c), grown on W(110) and strained thin films of Gd (b and d) grown on Mo(112). The images for the strained Gd films have been acquired for film thicknesses of approximately $15 \mathrm{ML}$ (b) and $50 \mathrm{ML}$ (e), respectively, while the unstrained Gd films are for submonolayer coverages as deposited (c) and annealed (a). The arrows indicate the Mo(112) substrate $<110>$ crystallographic direction.

is expanded by approximately $4 \%$ as compared to the "relaxed" Gd lattice [6]. While "unstrained" Gd films grown on W(110) develop a variety of coverage dependent submonolayer overlayer structures [13], the rectangular (possibly $\mathrm{Gd}(1012)$ ) ultra-thin structure is unique to the Gd film growth on $\mathrm{Mo}(112)$ [6].

The most prominent structural difference in the microstructure of the film growth of strained and unstrained $\mathrm{Gd}$, is the domain growth mode. Fig. 3 shows STM images for 
unstrained thin films of Gd (left) and strained thin films of Gd (right), for different film thicknesses. The STM images of Fig. 3 provide evidence for the substrate induced domain growth mode with a preferential growth direction for the strained Gd films, that is oriented along the $\mathrm{Mo}(112)$ corrugation direction (the substrate $<111>$ direction). The domain growth of the 15 ML Gd film (Fig. 3b) is characterized by long narrow stripes, approximately $15 \AA$ wide, that are separated by nearly equal distanced spacings (of approximately $25 \AA$ ). This nearly uniaxial growth of the Gd films grown on $\mathrm{Mo}(112)$ is consistent with the streaked hexagonal LEED pattern that is observed for the $15 \mathrm{ML}$ thick Gd films.

The STM images of the approximately $50 \mathrm{ML}$ thick Gd films are characterized by much wider, more "rectangular" shaped domains. The domains are approximately 100 to $500 \AA$ wide and a few percent of a micron long. We note that the termination of the short sides of these domains form angles of $60^{\circ}$ or $120^{\circ}$ with respect to the long sides, rather than $90^{\circ}$, indicative of the hexagonal crystalline ordering within these domains. The larger, more uniform domains of the thicker Gd films are consistent with the LEED pattern of the $50 \mathrm{ML}$ thick film, which is shown in Fig. 2c.

The domain growth mode of strained Gd grown on Mo(112) is very different from the growth mode of the "unstrained" Gd grown on W(110), which is characterized by a more uniform domain formation with no preferential growth direction [14-18]. The initial Gd/W(110) film growth is characterized by small, arbitrarily shaped Gd islands which become increasingly dense with increasing Gd coverage. For the higher Gd coverage, there is some indication for triangular shaped domain structures (Fig. 3c).

\section{CONCLUSIONS}

The preferential growth direction of the strained $\mathrm{Gd}$ films grown on $\mathrm{Mo}(112)$ is reflected in the altered band structure and possibly the distinct magnetic behavior [1-3]. For the thinner strained $\mathrm{Gd}$ films $(\mathrm{d}=15 \mathrm{ML}$ ) that are grown on $\mathrm{Mo}(112)$, the long but very narrow domains result in a anisotropic band dispersion of both the bulk and the surface electronic bands $[1,4,6]$. Along the $\langle 110\rangle$ substrate direction there is negligible dispersion in the strained Gd films which is in contrast to the Gd films grown on W(110) $[19,20]$. In the perpendicular direction (along $<11$ l $>$ of the substrate) the bands of the strained Gd films disperse, but different than those of the "unstrained" Gd $[6,19,20]$. For the thicker strained Gd films ( $\approx 50 \mathrm{ML}$ ), the significantly wider and larger domains result in dispersion along both Mo(112) substrate high symmetry directions, $<111>$ and $\langle 110\rangle$. 


\section{ACKNOWLEDGMENTS}

This work was funded by the NSF through grant DMR-94-96131.

\section{REFERENCES}

1. C. Waldfried, D. Welipitiya, T. McAvoy, E. Vescovo, and P. A. Dowben, submitted to Phys. Rev. Lett.

2. C. Waldfried, T. McAvoy, D. Welipitiya, E. Vescovo, and P. A. Dowben, submitted to Europhys. Lett.

3. C. Waldfried, D. Welipitiya, T. McAvoy, E. Vescovo, and P. A. Dowben, J. Appl. Phys., in press

4. C. Waldfried, D. N. McIlroy, and P. A. Dowben, Phys. Rev. B 54, 16460 (1996);

Erratum, Phys. Rev. B 56, 9973 (1997).

5. C. Waldfried, D. N. Mcllroy, D. Welipitiya, T. McAvoy, E. Vescovo, and P. A.

Dowben, J. Appl. Phys., in press.

6. C. Waldfried, D. N. Mcrlroy, and P. A. Dowben, J. Phys. Condens. Matter 9, 10615 (1997).

7. Dongqi Li, J. Pearson, S.D. Bader, D.N. McIlroy, C. Waldfried and P.A. Dowben, Phys. Rev. B 51, 13895 (1995).

8. D. Weller, S. F Alvarado, W. Gudat, K. Schroder, and M. Campagna, Phys. Rev. Lett 54, 1555 (1985).

$9 . \quad$ D. Weller and S. F. Alvarado, Phys. Rev. B 37 (1988) 9911.

10. D. Weller and S.F. Alvarado, J. Appl. Phys. 59 (1986) 2908.

11. T. McAvoy, C. Waldfried, J. Zhang, O. Zeybek, T. Bertrams, S. D. Barrett, and P.A. Dowben, submitted to Phys. Rev. A

12. G. P. Lopinski, J. A. Prybyla, P. J. Estrup, Surf. Sci. 296, 9 (1993).

13. J. Kolaczkiewicz and E. Bauer, Surf. Sci. 175, 487 (1986).

14. E. D. Tober, R. X. Ynzunza, C. Westphal, and C. S. Fadley, Phys. Rev. B 53, 5444 (1996).

15. R. Pascal, Ch. Zarnitz, M. Bode, R. Wiesendanger, Surf. Sci. 385, L990 (1997).

16. D. Weller, S. F. Alvarado, W. Gudat, K. Schroder, and M. Campagna, Phys. Rev. Lett. 54, 1555 (1985): D. Weller, S. F. Alvarado, J. Appl.

17. J. Kolaczkiewicz, E. Bauer, Surf. Sci. 175, 487 (1986).

Phys. 59, 2908 (1986).

18. R. G. White, M. H. Lee, N. P. Tucker, S. D. Barrett, and P. W. Murray, Phys. Rev. B 56, R10071 (1997).

19. Bongsoo Kim, A. B. Andrews, J. L. Erskine, Kwang Joo Kim, and B, N. Harmon. Phys. Rev. Lett. 68, 1931 (1992).

20. Dongqi Li, Jiandi Zhang, P. A. Dowben, and M. Onellion, Phys. Rev. B 45, 7272 (1992). 